Mansoura University

Faculty of Education

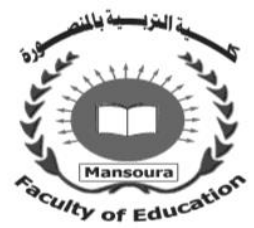

The Impact of Using Enrichment Activities Based on Web 2.0 Applications on Developing EFL Secondary Stage Students' Argumentative Writing Skills.

\author{
By \\ Yostina Gayed Sedky Gendy \\ A researcher in the Dept. of Curriculum and Instruction
}

Superwised by

Dr. Mervat M. El Hadidy

Associate Professor E. of

Curriculum\& Instruction

Mansoura University

Faculty of Education
Dr. Samah Rizk Hassan Associate Professor of Curriculum\& Instruction (TEFL) Mansoura University

Faculty of Education

Journal Of The Faculty Of Education-Mansoura University No. 112 - Oct. 2020 


\title{
The Impact of Using Enrichment Activities Based on Web 2.0 Applications on Developing EFL Secondary Stage Students' Argumentative Writing Skills
}

\author{
Yostina Gayed Sedky Gendy
}

\begin{abstract}
This study aimed to develop EFL argumentative writing skills. It is an important field that students should practice in secondary school academic writing. Given the writers should know how to collect information to build a good claim and make a right argumentation. This study explored the effects of teaching argumentative writing skills in an integrated online environment on EFL students at Talkha Secondary School for Girls Dakahleya Governorate. The participants of this study were EFL first year secondary stage students. In this study, the researcher used an EFLargumentative writing skills test to assess argumentative writing skills. Correlational analysis showed that the tools used in the study were valid and reliable enough to be used in the experiment, demonstrating significant coefficient in the argumentative writing skills. The experimental study results showed significant improvement after the post testing on the argumentative writing skills compared to pretesting and control group. The research ends with recommendations for further research.

Key words: argumentative writing skills, web 2.0, secondary stage,

EFL, Egypt, Enrichment activities.

\section{1- Introduction:}

Learning English as a foreign language EFL is very important today. So, using English in our life requires using its skills to communicate through the community. Education researches provide insights to language teachers and researchers who face some main issues. The first task is that much extant literature has focused on features of writing in education. Though, there is a lack of information to regard how students, especially non-native speakers (NNS), develop their writing skills and increase access to the discourse community and the common discourse community for what they are being prepared to join in their future jobs. Studies in English as a Second Language (ESL) context has taken concerns of acquisition and improvement of literacy to show that literacy should be explicitly incorporated within the disciplines in regular language and content courses (Lea, 2004, 2008; Purser, Donohue, Skillen, Peake \& Deane, 2008). In the EFL context,
\end{abstract}


however, researchers have recently started to address literacy development matters, resulting in a growing body of research.

Abrams (2001) shows this increasing research outlook as follows: "A lot of researches in second language acquisition have now examined the ability of using computer and online applications to provide students a forum in which they can create more language and more varied discourse functions than during in-class conferences, and in which they can become the beginners of discourse in place of simple followers of teacher-directed contact" (p. 490). Abrams (2001) noted that e-learning is now known as 'a great equalizer', being generally adopted for the benefit of maximal language use for communication reasons; he noted that "given its ability to result in a more evenly distributed amount of sharing (e.g., measured in number of words) among participants than face-to-face dialogues". Furthermore, most extant research has focused on the nature and genres of writing based on online search tasks that language learners in both ESL/EFL use in their learning process (Lea \& Street, 2006) and the ways in which students have to adapt to a language and discourse that is definite to a subject or discipline area . Up till now, little studies in the EFL context aimed to know how students improve their writing skills in academic settings, and enable them to gain access to the certain discourse community in the performance to their writing tasks with the help of recent technologies. In addition, investigations writing connections have not been directed by a consensual framework or unified theory of language processing (Alvermann, Unrau \& Ruddell, 2013, p. 959).

Argumentative writing is the type of writing in which the writer states his opinion on a controversial issue and supports his opinion with arguments for the purpose of getting the readers to change their mind on the controversial issue to reflect his point of view. It demands that the writer make the audience aware of why his or her understanding of the issue is reliable. Ultimately, the writer is successful when the reader accepts his or her opinions on the grounds of his or her discourse (Moore, 2009).

Argumentative writing is an essential skill through the school years and after. Academically, written argumentation supports students acquire knowledge. Moreover, written argumentation can be a leader to an increase in intrinsic motivation and performance of solving problems in the academic setting. It needs students to embrace a specific point of view and try to convince the reader to accept the same perspective or create a definite action. Therefore, the skill of argumentation has long been recognized as 
essential in academic studies at numerous levels (Chase, 2011, Moore, 2009, Qin, 2009).

In addition, the writer must also know the various elements that are specific to the kind of argumentation. According to Toulmin (1958), argumentation is composed of the following elements: a) claim, which is an assertion presented in response to a problems, b) data, which contains the evidence or grounds on which claims are made, c) warrant, which carries the link between the claim and data, d) backing, recognized as support of the warrant, e) qualifier, which is a term indicating the probable nature of the claim, and f) a reservation, which refers to the conditions under which the warrant will not hold and cannot support the claim. These components represent the basis of argumentative discourse and an organizational framework for writing an argumentative essay (Chase, 2011).

The main characteristics of Web 2.0 technologies, as (Schrum, L., \& Levin, B., 2009) clarify: are that they permit users to add and change content easily, collaborate and communicate directly in order to share, develop and distribute information. Web 2.0 technologies can play an essential role in developing the learning community e-learning students in online courses (Kearns, L., \& Frey, B., 2010); (Palloff, R., \& Pratt, K., 2009). According to Palloff, R., \& Pratt, K., (2009), Web 2.0 technologies have the talent to enhance the development of learning communities and reduce the isolation and distance touched by students in online courses.

\section{Review of Literature}

Writing is very important especially in EFL contexts. Writing is one of the four major skills in learning English as a second language. It consists of the basic rules of sentence structure, grammar and mechanics. EFL students do usually face obstacles in producing acceptable and communicative stretches of discourse. The purpose of this study is using a method to teach the skill of writing adopting the genre approach to teach writing. The purpose behind that is the belief that texts are different from each other in the way they are written and in the linguistic characteristics writers use to produce communicative texts that are appropriate by a given discourse community.

\section{Toulmin's model of argumentation}

Toulmin's model of argument analysis and Perelman and OlbrechtsTyteca's new rhetorical outline of argumentative methods have involved much interest. It instilled new viewpoints in the study of argumentation. It can be said nonetheless, that these writers generally have engaged in their thinking along the line of Aristotelian (or classical) logic, dialectic and 
rhetoric. In the 1970s and the 1980s, there were tries to study argumentation using a linguistic/pragmatic viewpoint too. Fogelin (1978) treats arguments as language use and studies arguments in daily life by applying the speech act theory of Austin (1970) and the conversational analysis of Grice (1967). Other studies that employ a similar method in their argument analyses include Quasthoff (1978),Schiffrin (1985), and van Dijk (1984, 1987).

Toulmin (1958) indicated three main parts to form an argument: claim, grounds (or data); and warrant. Later Toulmin goes on to assert that in an extended argument structure, there may be some second-level element such as backing; qualifier and rebuttal.

\section{Persuasive writing and augmentative writing}

Persuasive writing and augmentative writing aren't the same. Persuasive writing uses feelings and emotions to persuade the reader with a specific idea. Its reasons are to convince the reader. (Hillocks, 2011)

Persuasive writing is a kind of augmentative writing. The writer uses the persuasive writing to convince the reader with his/her point of view arguing against or for this point of view. (Abd El Maksoud, 2014)

Persuasion is not only reached through an appeal to reason, of which argument plays an important part, it can also be achieved throughout an appeal to audiences' emotions, and to the audience's perception of the speakers' character or personality. In short, in effective persuasion, three types of appeals are essential: rational affective and credibility. That is, if an audience is to be persuaded, they need to:

(1) Be persuaded by reasons and evidence rational appeal.

(2) Be engaged emotionally affective appeal.

(3) Trust the writer credibility appeal (Lauer, et. al. 1991: 138).

Persuasion as an aim in rhetoric is outside the realms of argumentation theories.

\section{Types of writing}

There are so many kinds of writing, persuasive, narrative, descriptive expository and argumentative writing.

In expository writing the writer's purpose is to tell or clarify the topic to the reader.

In persuasive writing the writer shapes his/her opinion and tries to affect the reader.

In descriptive writing the writer uses all his/her five senses to paint a picture for the reader. This writing contains imagery and specific details.

In narrative writing the writer tells a story. The story could be fact or fiction. 
The argumentative writing is very essential so this study will focus on developing this kind of writing.

\section{Web 2.0}

One of the most important ways of 'interaction and immersion' is facilitated in language lessons today through the use of interactive webbased technologies such as Web 2.0 tools. Web 2.0 is an online computing platform. This idiom, which is nowadays a common term, was coined by Tim O'Reilly at the O'Reilly Media Web 2.0 technology conference in 2004. The idea of Web 2.0 has totally changed our thinking about Internet usage and teaching modalities supported by the Internet. For years, using the primarily passive Internet involved of one-way searching for and retrieving of information from the Web-now retroactively referred to as "Web 1.0." Web 1.0 relied on installed software. Nowadays, Web 2.0, that uses a web browser rather than installed software, has given a new meaning to Internet searching and use.

\section{Schoology}

Schoology is a talented educational tool for meeting both present and future challenges of teaching and learning in the $21 \mathrm{st}$ century. Schoology.com is a free teaching tool, which helps teachers to manage classroom information. It is a collaborative platform for teachers, students, and parents. The reason for improving and incorporating Schoology in schools is to interact with school community in the technology-supported classroom to improve students' learning. This technology-supported instruction creates active educational support that can be fitted to new ideas from teachers and students.

Schoology supports an intimate relationship between the educational organizations and technology developers and serves as a catalyst to empower teaching and educational efficiency at different levels of any environment (i.e., K-12 education, higher education, corporate). To evaluate its value to teachers and students, it is important to asses if the Schoology website is appropriately aligned with students' learning and literacy development in today's classrooms. If the Schoology website and system does what it claims, teachers can use it to help assure the promotion of students' motivation to share their ideas and solve numerous problems for the benefit of individual or community. This Schoology website provides an integrated platform for Student Information Management System (SIS) beyond the typical learning management system (LMS). It also suggests an advanced API (Application Programming Interface) for helping teachers concentrate more on an effective teaching instead of administrative 
responsibilities. Schoology has three account options for teachers, students, and parents that are integrated with classroom organization's applications. These classroom features are improved for schools and can create active educational support for teachers and students, empower teachers by creating a collaborative learning environment for students, integrate experiences among educational stakeholders, and advance academic achievement and success in schools (Biswas, 2013).

The Schoology website is reviewed considering the following three design criteria from technology supported instruction by (Cummins, Brown, \& Sayers, 2007):

Provide cognitive challenge and chances for deep processing of meaning.

Promote self-regulated activity for collaborative inquiry.

Focus on multi literacies in the twenty-first century need.

Schoology website is appropriately allied with the students' learning and literacy activities in the classroom today. Through the Schoology website, teachers can ensure students' inspiration to share their ideas and solve several problems for the benefit of student or school community Cummins et al. (2007).

\section{Enrichment activities}

Enrichment activities are cross-curricular activities which are perfect for students with extended day programs. Adjunct activities \& programs, enrichment activities are held either during or after school hours. These activities complement the classroom instructions and textbook material.

\section{The pilot Study}

In order to determine the actual level of first year secondary school students' argumentative writing skills, the researcher designed a writing test to investigate the lack of argumentative writing skills among the first year secondary stage students in Talkha secondary school for girls. The test consisted of a writing task based on the student book of the first year "Hello". The researcher used a rubric to assess the students standards in the classroom and the results are shown in the table below:

Table (1):

Results of the Argumentative writing test of the pilot study

\begin{tabular}{|l|l|l|l|}
\hline Percentage & SD deviation & Mean & No. of students \\
\hline $26.9 \%$ & $\mathbf{1 . 8 3}$ & $\mathbf{2 . 6 9}$ & $\mathbf{2 5}$ \\
\hline
\end{tabular}

The pilot study showed that argumentative writing skills need to be improved. 


\section{Statement of the Problem}

Based on the literature, recommendations of other studies, the researcher's observations and the results of the pilot study, the problem of the study was stated as follows:

"EFL First year secondary stage Students exhibited low argumentative writing skills. Therefore, the aim of this study was to investigate the effectiveness of using enrichment activities based on web 2.0 that might develop first year secondary stage students' argumentative writing skills. Given this, the researcher wanted to provide first year secondary students with an opportunity to increase their argumentative writing skills through participating argumentative writing using enrichment activities based on web 2.0 activities"

\section{Questions}

The problem of the study was tackled through answering the following questions:

1-What is the current level of first year secondary stage students' EFL argumentative writing skills?

2- What are the enrichment activities based on web 2.0 that can contribute to develop EFL argumentative writing skills?

3- What is the effectiveness of the enrichment activities based on web 2.0 in enhancing EFL argumentative writing skills of first year secondary stage students?

\section{Hypotheses}

The current study attempted to verify the following hypotheses:

1-There is a statistically significant difference at 0.05 level between the mean score of the experimental group and the control group students on the post-administration of the argumentative writing test in favor of the treatment group.

2-There is a statistically significant difference at 0.05 level between the mean scores of the experimental group students on the pre-and postadministration of argumentative writing test in favor of the post one.

\section{Significance}

The current study would contribute to:

\section{(a) The secondary stage English teachers:}

- Raising secondary stage EFL teachers' awareness of the crucial benefits the learners can gain from exposure to Enrichment Activities Based on Web 2.0 Applications tools to improve argumentative writing skills. 
- Encouraging instructors of English are encouraged to design activities that can foster meaningful engagement for their students both inside and outside the classroom.

-Enriching the knowledge of the secondary stage teachers to use argumentative writing skills using inside the classroom.

\section{(b) Secondary stage students}

- Developing the secondary stage students' argumentative writing skills.

-Motivating the secondary stage students to write and enhance their confidence to use the argumentative writing.

- Encouraging secondary stage students to take more active part in their own language learning by fostering autonomous learning in a classroom and non-classroom environment by using web 2.0 tools.

\section{(c) Researchers}

- Increasing the knowledge of the researcher, there have been no previous studies in the field of EFL education that have attempted to encourage EFL secondary school learners to use Enrichment Activities Based on Web 2.0 Applications to develop argumentative writing skills.

\section{(d) Curriculum designers}

- The study provides curriculum designers with a framework to begin creating new curricula supported by the Internet.

\section{Delimitations}

The present study was delimited to the following:

-A group of (25) first year secondary stage students of Talkha secondary school for girls.

-Some argumentative writing skills. (claim, data, warrant, qualifier, backing, rebuttal)

-The study is based on using Enrichment Activities Based on Web 2.0 Applications. (Google search, Schoology, What's app)

-Students' textbook Hello! For first year units four, five and six.

\section{Method}

\section{Participants}

The Participants of the study were 50 female students from Talkha secondary school for girls. The Participants were assigned into two groups, an experimental group and a control group; each group consisted of twenty five students. It is the first time for them to learn argumentative writing skills the experiment utilized a an argumentative writing skills test which was developed, validated and administered to the two groups to verify their homogeneity and equivalence in terms of argumentative writing skills learning and use of web 2.0 applications. The experimental group was 
taught through using enrichment activities based on web 2.0 applications, whereas the control group was taught through the textbook techniques. They were taught by the same English teacher. The experiment was conducted during the second term of the academic year 2019/2020.

Design

The present study adopted the quasi-experimental design, using an experimental group and a control group from two classes randomly. The experimental group was taught through the treatment i.e., studying argumentative writing skills via using enrichment activities based on web 2.0 applications, whereas the control group was taught argumentative writing skills through the traditional method that is suggested in the Teacher's Guide. The two groups were tested before and after the experiment.

\section{Instruments}

The instruments used in the study were as follows:

1- An argumentative writing checklist to determine the most important argumentative writing skills that should be mastered by the first year secondary stage students.

2- An argumentative writing skills Test designed by the researcher.

3- An argumentative writing rubric to score the argumentative writing skills test.

\section{Procedures of the Study}

The recent study was proceeding as follows:

1- Preparing the achievement writing tests (pretest and posttest).

2- Assessing the test validity by giving it to a group of teachers.

3- Assessing the test reliability through a pilot study.

4- Obtaining permission of a secondary school.

5- The same instructor taught the two groups.

6- Administering the writing pretest to both the treatment group and the control group.

7- Implementing the use of activities based on web 2.0 applications on the treatment group and the ordinary method on the control group.

8- Administering the writing posttest to both groups under the same conditions.

9- Finally, discussing the results, and providing a conclusion and recommendations.

Definition of terms

Argumentative writing skills 
Liu (2018) defined argumentative writing as the kind of writing that defines the point of view that the writer wants to convince the reader with to change the readers' point of view or belief and make anew point of view.

The researcher defines argumentative writing as using claim or premise, data, warrant and backing to create a point of view supported by evidence or reasons from lots of sources that enables the students to persuade someone to do, believe or accept your claim.

\section{Web.2}

The term Web 2.0 was founded by O'Reilly (2005) referring to a new generation of World Wide Web tools that allow users to create and share their own content. Web 2.0 applications can be described as technologies that facilitate online cooperation and interaction with users. This depends on the performance of users who need to be more dynamic and collaborative, generative, interactive (Anastasiades \& Kotsiadis, 2013).

\section{Enrichment activities}

English Enrichment offers the opportunity to students to learn, writes, and read within a variety of genres throughout the school year. It allows for extension of activities and skills taught in English class, in addition to extra creative writing units.

Enrichment activities are fun that helps students to be more engaged in their learning and retain more information. Enrichment programs are in general interactive and project focused, and challenge students to use old ideas in new ways, while bringing new concepts to light.

The description of enrichment is "meaningful teaching at a higher level for those who need it." Enrichment can include activities in:

Student government, music, art, drama, science, game strategy, new language.

All those activities give students an opportunity to improve and increase important skills. Though, these non-instructional enrichments usually happen outside the classroom, but they are also used inside the classroom.

\section{Results and discussions}

The first hypothesis stated that: There is a statistically significant difference between the post-test mean scores of the treatment and nontreatment groups on the argumentative writing post-test in favor of the treatment group. To test this hypothesis, a t-test for independent sample was employed. Table (1) includes the mean score, standard deviations (S.D), tvalue, and the level of significance in the pre-post administration of the EFL argumentative writing skills test. 
Table (1)

Results of t-test of the treatment group on the pre-post-administration of the argumentative writing skills test.

\begin{tabular}{|c|c|c|c|c|c|c|c|}
\hline Sig. (2-tailed) & D. $f(n-1)$ & $T$ & $S D$ & Mean & $N$ & Measurement & Domains \\
\hline \multirow{18}{*}{ Significant at 0.05} & \multirow{18}{*}{24} & \multirow{2}{*}{52.7} & .00000 & 1.0000 & 25 & Pre & \multirow{2}{*}{$\mathrm{S} 1$} \\
\hline & & & หVฯAq. & r,q ... & ro & Post & \\
\hline & & \multirow{2}{*}{52.7} & .00000 & 1.0000 & ro & Pre & \multirow{2}{*}{$\mathrm{S} 2$} \\
\hline & & & rVYA9. & $r, q r \ldots$ & ro & Post & \\
\hline & & \multirow{2}{*}{26} & .48990 & 1.3600 & ro & Pre & \multirow{2}{*}{ S3 } \\
\hline & & & $r \ldots$. & $r, 97 \ldots$ & ro & Post & \\
\hline & & \multirow{2}{*}{$1 \wedge, \varepsilon$} & $007 \vee \Lambda$. & 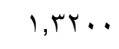 & ro & Pre & \multirow{2}{*}{ S4 } \\
\hline & & & หVฯงq. & r,qт.. & ro & Post & \\
\hline & & \multirow{2}{*}{$r, 1$} & rVฯAq. & $1, \cdot \wedge \ldots$ & ro & Pre & \multirow{2}{*}{ S5 } \\
\hline & & & $\varepsilon \wedge 99$. & (... & ro & Post & \\
\hline & & \multirow{2}{*}{$r, 0$} & หVนAq. & $1, \cdot 1 \ldots$ & ro & Pre & \multirow{2}{*}{ S6 } \\
\hline & & & $0 \ldots$. & $r, \tau, \ldots$ & ro & Post & \\
\hline & & \multirow{2}{*}{$I V, \varepsilon$} & תודוזי. & $1,1, \ldots$ & ro & Pre & \multirow{2}{*}{ S7 } \\
\hline & & & ovrro. & $r, \tau \ldots$ & ro & Post & \\
\hline & & \multirow{2}{*}{$\varepsilon r, \varepsilon$} & $\cdots \cdots$ & $1, \ldots$ & ro & Pre & \multirow{2}{*}{ S8 } \\
\hline & & & דודותו & $r, \wedge \wedge \ldots$ & ro & Post & \\
\hline & & \multirow{2}{*}{49.97} & 1.24097 & 8.9600 & ro & Pre & \multirow{2}{*}{ Total } \\
\hline & & & $1,291 \cdot 1$ & $r \cdot, 17 .$. & ro & Post & \\
\hline
\end{tabular}

Results in the above table illustrate that the estimated t-value was significant at 0.05 level. This reflects that there is statistically significant difference between the mean scores of the pre-post-administration of the argumentative writing skills test in the total score. This significant difference was in favor of the post-test.

The following figure shows the main scores of the study participants in the pre-post administration of the EFL argumentative writing skills test.

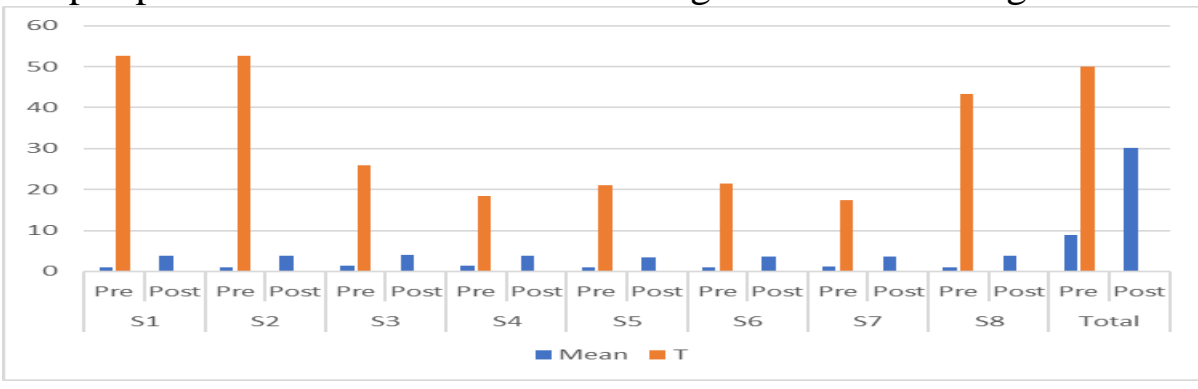




\section{Figure (1)}

Treatment and non-treatment groups mean scores on the pre-post

Hypothesis (2)

argumentative writing skills test

To test the second hypothesis which stated that there is a statistically significant difference between the pre and post-tests mean of the treatment group on the argumentative writing test in favor of the post- test.

Table (2) illustrates the effect size of the web 2.0 applications concerning the difference between the pre- and post- argumentative writing skills test on the treatment group.

\section{Table (2)}

Value of ( $\eta 2)$ and Levels of Effect Size

\begin{tabular}{|c|c|c|c|c|c|}
\hline $\begin{array}{l}\text { Level of } \\
\text { Effect Size }\end{array}$ & $\begin{array}{l}\text { Value of Eta - } \\
\text { square ( }(2)\end{array}$ & $\begin{array}{l}\text { D. f } \\
(\mathbf{n}-1)\end{array}$ & $\mathbf{T}$ & $\begin{array}{l}\text { Domains of the } \\
\text { dependent variable }\end{array}$ & $\begin{array}{l}\text { Independent } \\
\text { variable }\end{array}$ \\
\hline \multirow{9}{*}{ High } & 0.99 & \multirow{9}{*}{24} & 52.7 & S1 & \multirow{9}{*}{$\begin{array}{ll}\text { Web } & 2.0 \\
\text { applications } & \end{array}$} \\
\hline & 0.99 & & 52.7 & S2 & \\
\hline & 0.97 & & 26 & $\overline{S 3}$ & \\
\hline & 0.93 & & 18.4 & S4 & \\
\hline & 0.95 & & 21.1 & S5 & \\
\hline & 0.95 & & 21.5 & S6 & \\
\hline & 0.93 & & 17.4 & S7 & \\
\hline & 0.99 & & 43.4 & S8 & \\
\hline & 0.99 & & 49.97 & Total score & \\
\hline
\end{tabular}

Table (2) illustrates the effect size of the web 2.0 applications on the treatment group students in the eight skills of the argumentative writing skills. Results indicated that the effect size is high in post argumentative writing skills test. This difference between the pre- posttest can be illustrated similarly as follows:

$1.93 \%$ of the total variance of treatment group students' post- test in the first level making the right argument of the dependent variable (argumentative writing skills) can be attributed to the independent variable (web 2.0 applications).

2. $90 \%$ of the total variance of the second level (organization) can be attributed to the independent variable (web 2.0 applications).

$3.83 \%$ of the total variance of the third level (thesis statement) can be attributed to the independent variable (web 2.0 applications).

$4.92 \%$ of the total variance of the three levels of the dependent variable can be attributed to the independent variable (web 2.0 applications).

Results in tables (1) and (2) prove that the statistical differences between the pre- post argumentative writing skills test are in favor of the 
post-test. In addition, the size of these differences fosters the positive effect of the web 2.0 applications. Therefore, the second hypothesis of the study is proved and accepted.

\section{Discussion of results}

The above-mentioned results showed that there are statistically significant differences between the two groups in favor of the treatment group. As there is an apparent improvement in the argumentative writing skills of the students on the post-administration of the study instruments. These results can be attributed to the effect of the experimental treatment. To illustrate, in the beginning, the researcher used a web 2.0 application to help the students to develop their argumentative writing skills. After that, she used what's app program to allow students to engage in group/peer discussion about their points of weaknesses and strengths as well as gave some suggestions which helped them to improve their awareness as secondary students.

The researcher also implemented the web2.0 applications (Google search engine, What's app, Schoology) on the students, the applications developed the argumentative writing skills and its sub skills (thesis statement, organization and the right argument)

At the end of the treatment, the researcher asked the students to express their impressions and opinions about the treatment. In fact, most of their opinions were positive and they liked the treatment.

The treatment group achieved a high level of argumentative writing skills as shown in the previous results.

The level of the control group improved, as well, but it was not as high as that of the treatment group. This indicated that not only the experimental treatment alone had helped in promoting the participants' level, but they also gained more experience through their supervisor instructions during their teaching process. Besides, the regular way of training the student teachers is good, but it needs more modifications and there should be a variety of techniques in promoting student.

Results of the present study were consistent with the results of the studies conducted by Alexander (1997); Bransford, Brown, \& Cocking, (1999); Zhu (2001); Chuo (2004); Salem (2007); Ali (2011)

\section{References}

Abd El Maksoud, N. S. M. (2014). The effectiveness of writing conferences in pimproving EFL prep students' narrative and persuasive writing skills and syntactic complexity. Unpublished master thesis, Faculty of Education. Zagazig University. Egypt. 
Abrams, Z. I. (2001). Computer-mediated communication and group journals: Expanding the repertoire of participant roles. System, 29(4), 489-503.

Alvermann, D. E., \& Phelps, S. F. (1998). Content reading and literacy. Needham Heights, ma: Allyn \&Bacon.

Anastasiades, P. S., \& Kotsidis, K. (2013). The Challenges of Web 2.0 for education in Greece: A review of the literature. International Journal of Web-Based Learning and Teaching Technologies (IJWLTT), 8(4), 19-33.

Austin, J. L. (1970). Philosophical Papers. Edited by JO Urmson and GJ Warnock.

Biswas,S. (2013). Schoology-supported classroom management: A curriculum review. Northwest Journal of Teacher Education, 11(2). 12.

Chase, B. J. (2011). An analysis of the argumentative writing skills of academically underprepared college students (Doctoral dissertation, Columbia University).

Cummins, J., Brown, K., \& Sayers, D. (2007). Literacy, technology, and diversity: $\quad$ Teaching for success in changing times (pp. 91-111). Boston, MA: Pearson.

Fogelin, R. (1978). Understanding Arguments: An Introduction to Informal Logic. Informal Logic, 1(2).

Grice, H. P. (1967). Logic and Conversation". william James Lectures, Harvard University. In P. Cole and J. L. Morgan I ds.) Syntax and Semantics. Vol. 3. NY: Academic Press. 41-48.

Kearns, L. R., \& Frey, B. A. (2010). Web 2.0 technologies and back channel communication in an online learning community. TechTrends, 54(4), 41-51.

Lauer, Janice M., Gene Montague. Andrea Lunsford. and .Janei. Emig(1991). Four Worlds of Writing. 3rd ed. NY: Harper Collins Publishers.

Lea, M. R. (2004). Academic literacies: A pedagogy for course design. Studies in higher education, 29(6), 739-756.

Lea, M. R., \& Street, B. V. (2006). The" academic literacies" model: Theory and applications. Theory into practice, 45(4), 368-377. 
Liu, X. (2018). Research on the application of "Tree Analysis Diagram" to the teaching of English argumentative writing of the Chinese EFL learners. English Language Teaching,11(3), 137-152.

Moore, N. S. (2009). The effects of being a reader and of observing readers on fifth grade students argumentative writing. University of Delaware.

O'Reilly, T., \& McNamara, D. S. (2007). The impact of science knowledge, reading skill, and reading strategy knowledge on more traditional "high-stakes" measures of high school students' science achievement. American educational research journal, 44(1), 161-196.

Palloff, R. M., \& Pratt, K. (2009, August). Web 2.0 technologies and community building online. In 25th Annual Conference on Distance Teaching \& Learning. Madison, Wisconsin (pp. 4-7).

Purser, E. R., Skillen, J., Deane, M., Donohue, J., \& Peake, K. (2008). Developing academic literacy in context.

Qin, J. (2009). The analysis of Toulmin elements and use of sources in Chinese university EFL argumentative writing. Northern Arizona University.

Quasthoff, U. (1978). The Uses stereotype Everyday Argument'. Journal of Pragmatics. 2.1-48.

Schiffrin, D. (1985). Everyday argument: The organization of diversity in talk. Handbook of discourse analysis, 3, 35-46.

Schrum, L., \& Levin, B. B. (2009). Leading 21st-century schools: Harnessing technology for engagement and achievement. Corwin Press.

Toulmin, S. (1958). The Uses of Argument Cambridge University Press. Cambridge, UK.

Unrau, N. J., \& Ruddell, R. B. (2004). Theoretical Models and Processes of reading. Newark, NJ: International Reading Association.

Van Eemeren.F.H., Grootendorst R.,\&T.Krager(1987). Handbook of Augmentation Theory: A critical Survey of Classical background and Modem Studies. Dordrecht, Holland: Forris Publications. 